\title{
Coordination of cooperative promotion efforts with competing retailers in a manufacturer- retailer supply chain
}

\author{
Maryam Johari ${ }^{\mathrm{a}}$ and Seyyed-Mahdi Hosseini-Motlagh ${ }^{\mathrm{b}^{*}}$
}

${ }^{a}$ MSc. Student, School of Industrial Engineering, Iran University of Science and Technology, Tehran, Iran ${ }^{b}$ Assistant professor, School of Industrial Engineering, Iran University of Science and Technology, Tehran, Iran

\begin{abstract}
A B S T R A C T
In this paper, the issue of cooperative (co-op) promotion efforts is addressed in a two-stage supply chain (SC). The investigated SC includes one monopolistic manufacturer and two duopolistic retailers facing different market demands. The customers' demand is affected by both advertising efforts of the manufacturer and two retailers. Moreover, the retailers compete with each other on local advertising investments within the market. In order to boost the retailers' advertising level, it is assumed that the manufacturer pays a ratio of the retailers' advertising expenditures. We propose four non-cooperative game scenarios and one cooperative game. Non-cooperative models are established through both Stackelberg and Nash game between two echelons. Moreover, both Cournot and Collusion behaviors are assumed to be followed by two retailers. We develop a promotion cost sharing contract to achieve the channel coordination. Under cooperation model, all SC members seek to reach the highest profit for the entire SC by considering the bargaining power of the SC participants. In each game scenario the optimal solution and unique equilibrium are determined. In addition, a comparison on the advertising level of all SC members along with the value of participation rate are provided. In addition, the feasibility of the cooperative game is discussed and resulted.
\end{abstract}

\section{Introduction}

Nowadays, the competition in business environment has increased due to the development of technology, growing preferences of customers, globalizations, and shortening life cycle of products. Under such circumstances, supply chain (SC) mangers should apply different mechanisms to gain more market share. Promotion effort or advertising is one of the key tools which has extensively been used within service industry to intensify the image of brand name and stimulate instant sales (Giri \& Sharma, 2014). According to Huang et al. (2002), there are two kinds of advertising: (1) national advertising and, (2) local advertising. National promotion efforts, which are usually exerted by upstream members (e.g. manufacturer), are related to activities such as increasing brand awareness and popularity of product. While, the aim of down stream's (e.g. retailer) local advertising is to create potential consumers to the point of desire and action.

* Corresponding author

E-mail address: motlagh@iust.ac.ir (S.-M. Hosseini-Motlagh)

C 2018 Growing Science Ltd. All rights reserved.

doi: $10.5267 / j . u s c m .2017 .6 .004$ 
Cooperative advertising is a promotional strategy in which the manufacturer (supplier) aims to influence performance of the retailer (reseller) through paying a portion of the advertising cost invested by retailer (Bergen \& John, 1997). The co-op advertising can significantly boost the market demand and therefore enhance profitability of the overall SC (Xie \& Neyret, 2009). The co-op advertising has been extensively taken into account by both researchers and practitioners. A primary co-op advertising model was developed by Berger (1973). Chintagunta and Jain (1992), Li et al. (2002), Karray and Zaccour (2005), Xie and Neyret (2009), SeyedEsfahani (2011), Zhang et al. (2013), Liu et al. (2014), Chaab and Rasti-Barzoki (2016) investigated cooperative advertising models from various perspectives such as static, dynamic, good will, reference price and so forth. For more detailed information, the interested readers are referred to Jørgensen and Zaccour (2014) who comprehensively reviewed cooperative advertising models.

In the supply chain context, advertising decisions made by an individual member impact on the performance of the other SC members. Therefore, advertising policies in supply chain is often analytically investigated through game theory approach. Competition among various levels of SC can be performed through three scenarios i.e. Manufacturer Stackelberg, Retailer Stackelberg, and Vertical Nash. Moreover, there are mainly two behaviors followed by the SC downstream members: (1) Cournot, which is a popular competitive structure and members decide independently of each other and (2) Collusion, which is pursued among opponents as non-competitive arrangement. Under collusion behavior rival members (e.g. retailers) collaborate with each other to change the local promotion effort of a product to their benefit. Game theory approaches are substantially applied to evaluate the performance of co-op advertising issue within supply chain coordination.

Achieving channel coordination under co-op advertising games is a significant issue which leads to the improvement of SC performance (Dant \& Berger, 1996; Yue et al., 2006; Chaab \& Rasti-Barzoki, 2016). Whereas, under individually decision-making, the "double marginalization" phenomenon is occurred due to lack of coordination (Aust \& Buscher, 2012; SeyedEsfahani, 2011).

In this paper, the co-op advertising problem is addressed in a two-level SC including one monopolistic manufacturer and two duopolistic retailers facing different customers' demand. We take into account the impact of promotion efforts exerted by both the manufacturer and two retailers on the customers' demand, simultaneously. In the investigated SC, the retailers compete with each other on local promotion efforts in the market. In addition, the manufacturer supports a portion of the retailers' expenditures on promotion efforts to enhance the local advertising. The co-op advertising in the SC is developed under three different decision-making strictures: (1) decentralized, (2) centralized and, (3) coordination model. First, the decentralized structure is modeled through four non-cooperative game scenarios i.e. Nash-Cournot, NashCollusion, Stackelberg-Cournot, and Stackelberg-Collusion. Meanwhile, both Nash and Manufacturer Stackelberg game scenarios are developed between two echelons. Furthermore, we consider the circumstances in which either Cournot or Collusion behaviors are adopted by two retailers. Under the centralized model, the cooperative game scenario is proposed under situation in which three SC participants aim to maximize entire SC profit. Afterwards, to achieve channel coordination, a promotion cost sharing contract is proposed and the feasibility of the developed cooperation game is analyzed. Using the proposed contract, the extra SC profit will be divided among SC members through suggested bargaining model.

The remainder of the paper is designed as follows: A relevant literature is surveyed in section 2. Section 3 provides notations. Section 4 describes the structure of the investigated SC. Section 5 investigates decentralized decision making model through four non-cooperative game structures. In section 6 , cooperation decision making model is explained. Channel coordination model along with the feasibility of the cooperation model is analyzed in Section 7. Section 8 develops bargaining problem in order to divide the obtained profit among SC members. Finally, conclusions and future directions are summarized in section 9 . 


\section{Literature review}

In recent years, there has been much attention on supply chain coordination under various structures. Some papers have investigated channel coordination without considering competition (Nematollahi et al., 2017a; Nematollahi et al., 2017b; Heydari et al., 2017; Chaharsooghi et al., 2011; Sajadieh \& Akbari Jokar, 2009; Johari et al., 2017, Hojati et al., 2017). On the other hand, some studies have been carried out on supply chain coordination by considering competition. The current paper is closely relevant to the research stream of cooperative promotion effort. In order to justify the position of the paper and reveal contributions, the related literature is surveyed in the following.

Co-op advertising was adopted by Berger (1973) for the first time. He examined the promotion effort problem in a manufacturer-retailer chain. Afterwards, the impact of local advertising investment on the customers' demand was evaluated by many scholars under competitive and non-competitive environment. Tiaojun et al. (2010) investigated an SC comprising one manufacturer and one monopolistic retailer. The retailer sold one seasonal product within a retail market. In order to stimulate the customers' demand, the retailer was considered to spend on local advertising expenditure. Their proposed model was examined under both retailer's decision and cooperation scenarios. They exerted a markdown money-cooperative advertising (MMCA) approach to coordinate the investigated co-op SC. Further, Mirzaee et al. (2012) considered a two echelon SC where one manufacturer sells one product through two competing retailers. In their model, the volume of sales was assumed to be affected by retailers' advertising level through imposing investment in promotion effort. The manufacturerStackelberg game was studied in their model along with cooperation scenario. They obtained channel coordination through combined quantity discount and advertising cost sharing contracts. Moreover, Tsao and Sheen (2012) formulated a two-stage SC including one supplier and two competing retailers. In their model, two retailers compete with each other on promotion effort. Their co-op model was considered through retailer's decision and cooperation game scenarios. To reach the supply chain coordination, they applied cost sharing contract in their considered SC. Subsequently, Dai and Chao (2013) modeled an SC including one firm and multiple sales agents facing random agents' advertising dependent demand. They investigated SC which was constructed under supplier-Stackelberg game. To obtain the realized value of the market demand, the firm offered menu of compensation contracts to the sales agents. In another research, Giri and Sharma (2014) established a two-level SC consisting one manufacturer and two competing retailers. Two retailers competed with each other on local advertising. Their SC model was investigated under manufacturer-Stackelberg game scenario where the manufacturer as an SC leader determines wholesale price for each retailer.

Most of the abovementioned researches on cooperative promotion effort considered only the effect of local promotion effort on the market demand, whereas the national promotion effort can induce the volume of sales. To this end, few researchers developed co-op advertising models in which market size was assumed to be affected by both national and local promotion effort. Wang et al. (2011) developed a co-op advertising problem comprising one monopolistic manufacturer and two duopolistic retailers. In their model, market demand was influenced by both local and national adverting expenditure. In addition, their constructed SC was examined under four game structures, Stackelberg-Cournot, Stackelberg-Collusion, Nash-Cournot and Nash-Collusion. To achieve channel coordination, they used cost sharing contract. Later, Zhang et al. (2013) suggested a dynamic co-op promotion effort in a two-echelon SC. Their investigated SC included one retailer and one manufacturer where both members carried out advertising investment. In their model, the consumer's reference price and goodwill for one product were considered to be promotion effort. Their co-op SC was examined under manufacturer-Stackelberg and cooperation scenarios. Two-way subsidy contract was considered to coordinate the SC in their model. Another study, Alaei et al. (2014) analyzed a manufacturer-retailer SC. In their SC, the manufacturer sells its product through two competing retailers. The competition between two retailers was considered to be advertising costs. Market demand was considered to be the same for two retailers. Four non-cooperative game scenarios along with one cooperation model were 
examined in their model. They offered cost sharing contract to split the achieved SC profit among parties. Recently, Zhou et al. (2017) modeled a co-op promotion effort and ordering problem in a manufacturer-retailer SC. The manufacturer sells one product through one retailer. In their SC, both manufacturer's national promotion effort and retailer's local promotion effort affected the customers' demand. They examined the investigated SC under manufacturer-Stackelberg and cooperation games. In addition, their co-op SC was coordinated through buy back contract.

In the previous literature on co-op promotion effort by considering both national and local advertising, there has been less attention on the competition of retailers. In addition, according to Table 1, there are few researches establishing various game scenarios and different behaviors of competing retailers under co-op advertising. To create a more realistic model, in the current study, we integrate the impacts of national and local promotion effort on customers' demand where two competing retailers face with different potential market demands. Moreover, we consider various game scenarios within co-op advertising SC into account to evaluate the influences of diverse competitive behaviors of SC participants on the co-op promotion effort issue along with all SC members' benefits. Meanwhile, motivation of all SC parties to act under each game structure is specified. Finally, we propose a promotion cost sharing contract along with a bargaining Nash problem to achieve channel coordination and moreover distribute the obtained SC profit among all SC members properly.

\section{Notations}

Table 2 provides the notations used for the decision variables and parameters of the developed models.

Table 2

Notations

\begin{tabular}{ll}
\hline Decision variables \\
\hline $\mathrm{a}_{\mathrm{i}}$ & Local advertising investment of retailer i \\
$\mathrm{A}$ & National advertising investment of manufacturer \\
$\varnothing$ & Fraction of the local advertising investment paid by the manufacturer to retailer \\
\hline Parameters & \\
\hline $\mathrm{D}\left(\mathrm{a}_{\mathrm{i}}, \mathrm{A}\right)$ & The retailer i's demand volume \\
$\alpha_{\mathrm{i}}$ & Initial demand for retailer i \\
$\lambda$ & The demand sensitivity of retailer i on its own advertising \\
$\gamma$ & The demand sensitivity of retailer i on its rival's advertising \\
$\delta$ & The demand sensitivity on the national advertising \\
$\mathrm{m}_{0}$ & The retailer i's marginal profit \\
$\mathrm{m}_{1}$ & The manufacturer's marginal profit \\
$\theta$ & The proportion of marginal profit of manufacturer per unit towards the retailers' \\
\hline
\end{tabular}




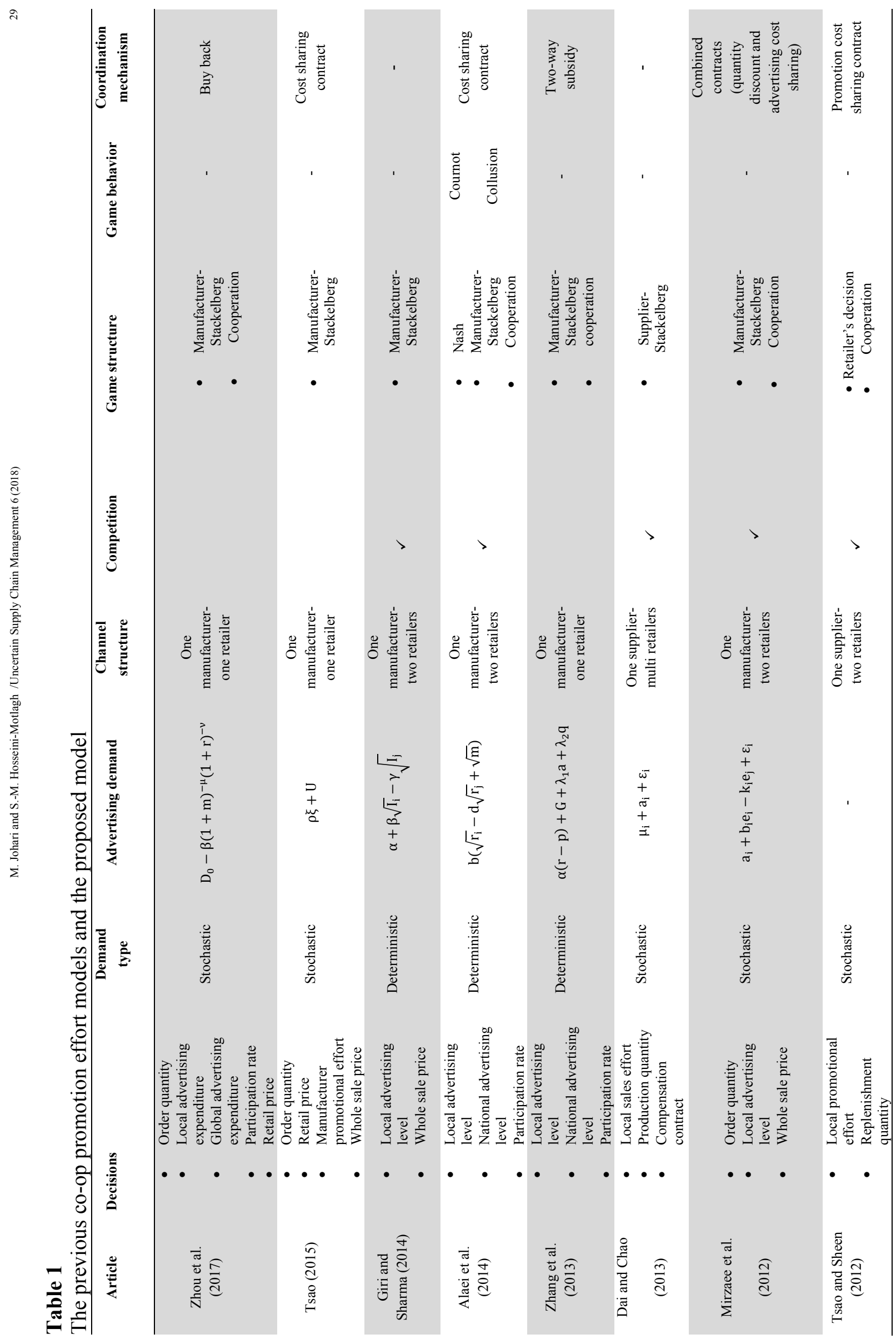




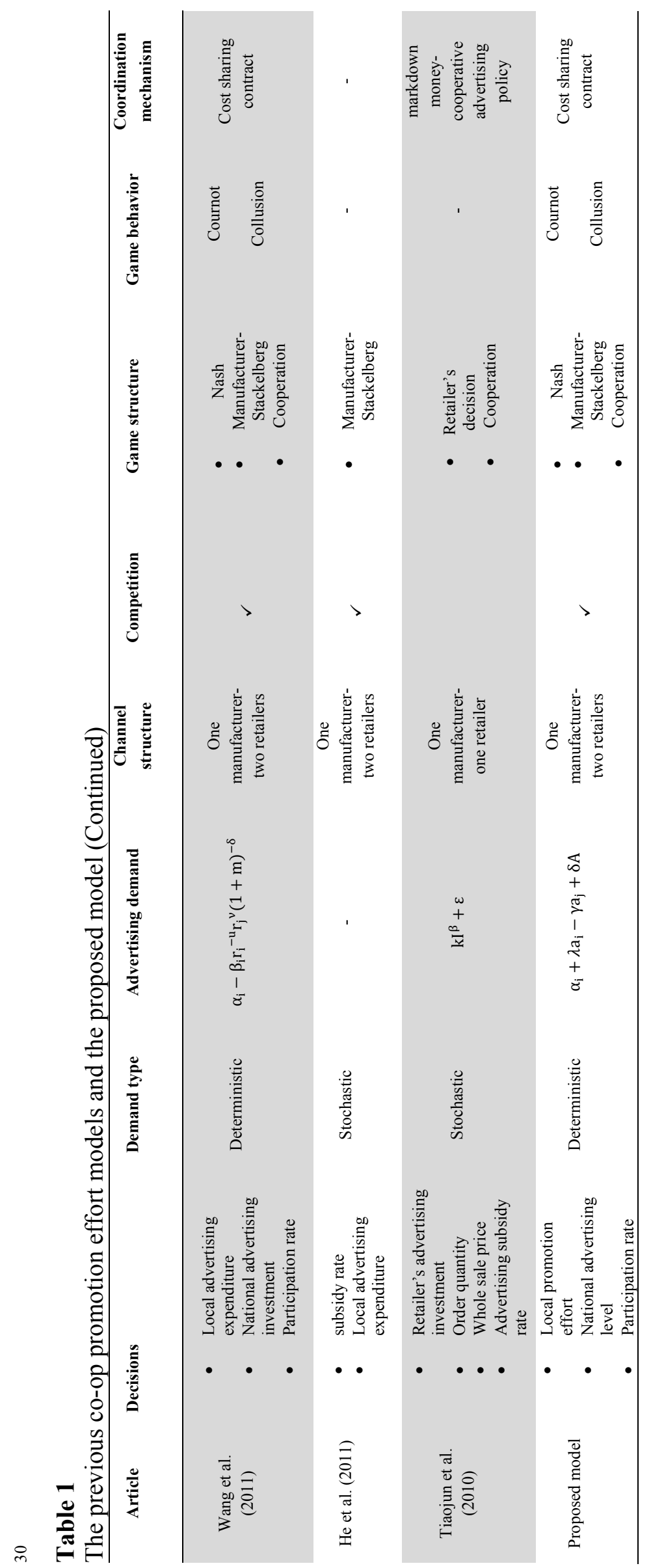




\section{Two-level supply chain model}

In this research cooperative promotion effort policies in a two-echelon supply chain is investigated. The SC under consideration includes one monopolistic manufacturer who sells its product through two duopolistic retailers. The retailers compete with each other on local advertising expenditures within a market. The manufacturer invests in national advertising in order to affect potential consumers and expand brand knowledge and distinctions. On the other hand, the retailers invest in local promotion efforts to motivate customers' buying behaviors. In addition, the manufacturer shares a fraction of each retailer's promotion effort expenditures, $\emptyset(0 \leq \emptyset<1)$ to persuade the both retailers to spend more investment in the local advertising. The retailers face with different customer's demand depending on advertising costs given by $D\left(a_{i}, A\right)=\alpha_{i}+\lambda a_{i}-\gamma a_{j}+\delta A(i, j=1,2, i \neq j)$ in which the national advertising investment of manufacturer and the local advertising expenditure of retailer $i$ have positive impacts on the product demand of the retailer $i$. However, considering the competition behavior between two retailers, local advertising cost of retailer $\mathrm{j}$ will have a negative effect on the demand of retailer $i$. This paper analyzes four non-cooperation game scenarios and one cooperative game. In each of the non-cooperation models, the Stackelberg/Nash game is played between the echelons and the duopolistic retailers follow the two Cournot and Collusion behaviors. The Cournot behavior is based on the retailers' simultaneous move, and the collusion is based on their cooperation. In the Stackelberg setting, the interaction between two echelons is considered to be the manufacturer-Stackelberg where the manufacturer is a leader and the retailers are considered as followers. Under this scenario, the manufacturer sets its optimal national advertising investment in order to maximize its profit, while the duopolistic retailers determine their local promotion efforts that maximize their profit considering the information obtained from the manufacturer. While, in the Nash setting, the members of upstream and downstream echelons choose their decisions simultaneously and non-cooperatively to maximize their profits. Fig. 1 illustrates the proposed competitive manufacturer-retailers SC.

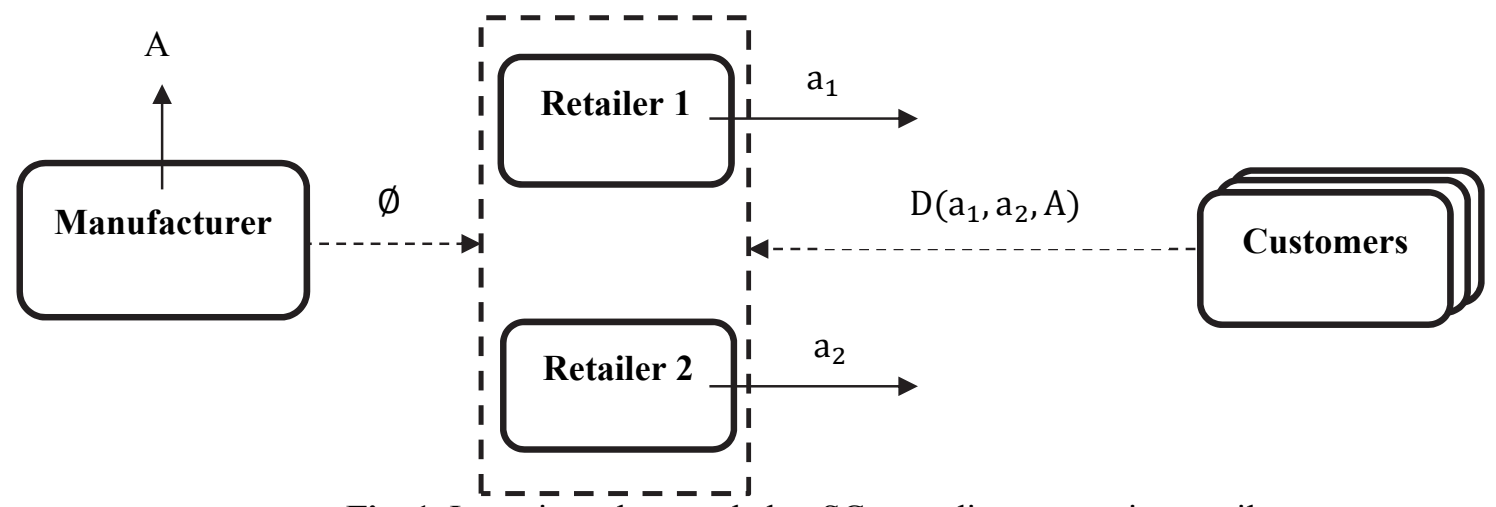

Fig. 1. Investigated two-echelon SC regarding competing retailers

\section{Decentralized decision-making}

In decentralized channel the expected profit functions of the retailers and manufacturer can be represented as Eqs. (1-2), respectively. The profit function of retailers is defined based on sales revenue and local promotion effort expenditures.

$$
\mathrm{TP}_{\mathrm{i}}\left(\mathrm{a}_{\mathrm{i}}\right)=\mathrm{m}_{0}\left(\alpha_{\mathrm{i}}+\lambda \mathrm{a}_{\mathrm{i}}-\gamma \mathrm{a}_{\mathrm{j}}+\delta \mathrm{A}\right)-(1-\emptyset)\left(\frac{1}{2} \mathrm{a}_{\mathrm{i}}^{2}\right), \quad \mathrm{i}=1,2, \mathrm{j} \neq \mathrm{i}
$$

While, the manufacturer's profit function includes sales revenue, national advertising investment and a fraction of local promotion effort expenditures of two retailers.

$$
\mathrm{TP}_{m}(\mathrm{~A}, \emptyset)=\mathrm{m}_{1}\left(\left(\alpha_{1}+\alpha_{2}\right)+a_{1}(\lambda-\gamma)+a_{2}(\lambda-\gamma)+2 \delta \mathrm{A}\right)-\frac{1}{2} \mathrm{~A}^{2}-\emptyset\left(\frac{1}{2} \mathrm{a}_{1}^{2}+\frac{1}{2} \mathrm{a}_{2}^{2}\right)
$$


In our model, it is considered that the marginal profit of manufacturer corresponds to retailer's marginal profit as expressed in Eq. (3).

$$
\mathrm{m}_{1}=\theta \mathrm{m}_{0}
$$

Under decentralized decision making model, we investigate four non-cooperative scenarios i.e., NashCournot, Nash-Collusion, Stackelberg-Cournot, and Stackelberg-Collusion as described in subsections 5.1-5.4, respectively.

\subsection{Nash-Cournot model}

In this model, the Cournot behavior is adapted by two retailers and vertical Nash game is played between SC levels. Meanwhile, the adverting expenditures and participation ratio decisions are made by three SC participants simultaneously and non-cooperatively. Under Nash scenario considering Cournot behavior of two retailers, the optimal decision variables are calculated as follows which are displayed by Nash-Cournot (NCt).

Proposition 1. Nash-Cournot (NCt) solution:

Condition 1: If $\theta<\frac{\gamma \lambda}{2 \delta^{2}}-\frac{\alpha_{\mathrm{i}}}{2 \delta^{2} \mathrm{~m}_{0}}-\frac{\lambda^{2}}{4 \delta^{2}}$, there exist no equilibrium.

Condition 2: If $\theta>\frac{\gamma \lambda}{2 \delta^{2}}-\frac{\alpha_{i}}{2 \delta^{2} m_{0}}-\frac{\lambda^{2}}{4 \delta^{2}}$, there exist unique equilibrium as Eqs. (4-6).

$$
\mathrm{A}^{\mathrm{NCt}}=2 \theta \mathrm{m}_{0} \delta
$$

and

$$
\emptyset^{\mathrm{NCt}}=0
$$

and

$$
\mathrm{a}_{\mathrm{i}}^{\mathrm{NCt}}=\mathrm{m}_{0} \lambda
$$

Proof. The first-order derivative of the profit function of manufacturer and retailer $i$ w.r.t. their decision variables are calculated as follows:

$$
\frac{\partial \mathrm{TP}_{\mathrm{m}}(\mathrm{A}, \emptyset)}{\partial \mathrm{A}}=2 \theta \mathrm{m}_{0} \delta-\mathrm{A}=0
$$

and

$$
\frac{\partial \mathrm{TP}_{\mathrm{m}}(\mathrm{A}, \emptyset)}{\partial \varnothing}=-\frac{1}{2} \mathrm{a}_{1}^{2}-\frac{1}{2} \mathrm{a}_{2}^{2}<0
$$

According to Eq. (8), since $0 \leq \emptyset<1$, thus, the optimal value of the participation rate, $\emptyset$ is zero.

$$
\frac{\partial \mathrm{TP}_{\mathrm{i}}\left(\mathrm{a}_{\mathrm{i}}\right)}{\partial \mathrm{a}_{\mathrm{i}}}=\mathrm{m}_{0} \lambda-(1-\emptyset) \mathrm{a}_{\mathrm{i}}=0 \quad, \mathrm{i}=1,2
$$

Hence, the optimal value of the local promotion effort is determined as $a_{i}=\frac{m_{0} \lambda}{1-\varnothing}$ and by considering $\varnothing=0$, we have a unique solution for the promotion effort of retailer $i$ as Eq. (6). 
Furthermore, the second-order derivative of the profit functions of manufacturer and retailer $i$ w.r.t. their decision variables are as follows:

$$
\frac{\partial^{2} \mathrm{TP}_{\mathrm{m}}(\mathrm{A}, \emptyset)}{\partial \mathrm{A}^{2}}=-1<0
$$

and

$$
\frac{\partial^{2} \mathrm{TP}_{\mathrm{i}}\left(\mathrm{a}_{\mathrm{i}}\right)}{\partial \mathrm{a}_{\mathrm{i}}^{2}}=-(1-\emptyset)<0 \quad, \mathrm{i}=1,2
$$

Eqs. (10-11) demonstrate that the profit function of both retailers and manufacturer are concave and so the obtained solutions are optimal.

Hence, by substituting the achieved decision variables into the profit function of retailer $i$ we obtain:

$$
\mathrm{TP}_{\mathrm{i}}=\mathrm{m}_{0} \alpha_{\mathrm{i}}+\frac{\lambda^{2} \mathrm{~m}_{0}^{2}}{2}-\gamma \mathrm{m}_{0}{ }^{2} \lambda+2 \theta \delta^{2} \mathrm{~m}_{0}^{2},
$$

where, if $\theta<\frac{\gamma \lambda}{2 \delta^{2}}-\frac{\alpha_{\mathrm{i}}}{2 \delta^{2} \mathrm{~m}_{0}}-\frac{\lambda^{2}}{4 \delta^{2}}$, the retailers' profit will be negative and then under this condition there is no viable solution.

According to Proposition 1 the unique equilibrium solution will be achieved under specific condition.

\subsection{Nash-Collusion model}

In this model, two retailers carry out the collusion behavior and also a vertical Nash game is played between two SC levels. Considering collusion behavior, two retailers are willing to cooperate with each other on maximization of their profits. Under Nash scenario regarding Collusion behavior of two retailers, the optimal decision variables are defined as follows which are denoted by Nash-Collusion $(\mathrm{NCn})$.

Moreover, within Collusion behavior the retailers' profit function is explained as Eq. (13). In this scenario, the profit function of manufacturer is the same as Eq. (2).

$$
\begin{aligned}
\operatorname{TP}_{\mathrm{R}}\left(\mathrm{a}_{1}, \mathrm{a}_{2}\right)= & \operatorname{TP}_{1}\left(\mathrm{a}_{1}\right)+\mathrm{TP}_{2}\left(\mathrm{a}_{2}\right) \\
& =\mathrm{m}_{0}\left(\left(\alpha_{1}+\alpha_{2}\right)+\mathrm{a}_{1}(\lambda-\gamma)+\mathrm{a}_{2}(\lambda-\gamma)+2 \delta \mathrm{A}\right) \\
& -\frac{(1-\emptyset)}{2}\left(\mathrm{a}_{1}^{2}+\mathrm{a}_{2}^{2}\right)
\end{aligned}
$$

Proposition 2. Nash-Collusion (NCn) solution:

$$
\mathrm{A}^{\mathrm{NCn}}=2 \theta \mathrm{m}_{0} \delta
$$

and

$$
\emptyset^{\mathrm{NCn}}=0
$$

and

$$
\mathrm{a}_{\mathrm{i}}^{\mathrm{NCn}}=\mathrm{m}_{0}(\lambda-\gamma)
$$

Proof. Under this model, since the profit function of manufacturer is the same as Eq. (2), thus, the optimal participation rate and national advertising investment are the same as NCt solution.

The first-order derivative of $\operatorname{TP}_{\mathrm{R}}\left(\mathrm{a}_{1}, \mathrm{a}_{2}\right)$, for the retailer i w.r.t. local promotion effort is indicated as Eq. (17). 
$\frac{\partial \mathrm{TP}_{\mathrm{R}}\left(\mathrm{a}_{\mathrm{i}}, \mathrm{a}_{\mathrm{j}}\right)}{\partial \mathrm{a}_{\mathrm{i}}}=\mathrm{m}_{0}(\lambda-\gamma)-(1-\emptyset) \mathrm{a}_{\mathrm{i}}=0$.

Therefore, the optimal value of the local promotion effort is determined as $a_{i}=\frac{m_{0}(\lambda-\gamma)}{1-\varnothing}$ and when $\emptyset=$ 0 , the unique solution for the local promotion effort is determined as Eq. (16).

To prove the concavity of the profit of retailers w.r.t. $a_{i}$ and $a_{j}$, the Hessian matrix of $\operatorname{TP}_{R}\left(a_{1}, a_{2}\right)$ with respect to the $a_{i}$ and $a_{j}$ can be calculated as follows. If the Hessian is negative definite, then $\operatorname{TP}_{R}\left(a_{1}, a_{2}\right)$ is concave w.r.t. $a_{i}$ and $a_{j}$.

$\mathrm{H}\left(\mathrm{TP}_{\mathrm{R}}\right)=\left[\begin{array}{cc}\frac{\partial^{2} \mathrm{TP}_{\mathrm{R}}}{\partial \mathrm{a}_{1}{ }^{2}} & \frac{\partial^{2} \mathrm{TP}_{\mathrm{R}}}{\partial \mathrm{a}_{1} \partial \mathrm{a}_{2}} \\ \frac{\partial^{2} \mathrm{TP}_{\mathrm{R}}}{\partial \mathrm{a}_{2} \partial \mathrm{a}_{1}} & \frac{\partial^{2} \mathrm{TP}_{\mathrm{R}}}{\partial \mathrm{a}_{2}{ }^{2}}\end{array}\right]$

where

$$
\mathrm{H}_{11}=\frac{\partial^{2} \mathrm{TP}_{\mathrm{R}}}{\partial \mathrm{a}_{1}^{2}}=-(1-\mathrm{t})<0
$$

and

$$
\begin{aligned}
& \frac{\partial^{2} \mathrm{TP}_{\mathrm{R}}}{\partial \mathrm{a}_{1} \partial \mathrm{a}_{2}}=\frac{\partial^{2} \mathrm{TP}_{\mathrm{R}}}{\partial \mathrm{a}_{2} \partial \mathrm{a}_{1}}=0 \\
& \frac{\partial^{2} \mathrm{TP}_{\mathrm{R}}}{\partial \mathrm{a}_{2}^{2}}=-(1-\mathrm{t})<0 \\
& \mathrm{H}_{22}=(1-\emptyset)^{2}>0
\end{aligned}
$$

As observed, the Hessian matrix is negative definite. Thus, $\operatorname{TP}_{R}\left(a_{1}, a_{2}\right)$ is concave w.r.t. $a_{i}$ and $a_{j}$.

Proposition 2 implies that the Nash-Collusion game always results in a unique equilibrium solution.

\subsection{Stackelberg-Cournot model}

In this model, Stackelberg game is followed by two SC levels where the manufacturer is considered to be the SC leader and both SC retailers are the followers. In addition, the Cournot behavior is pursued by two duopolistic retailers. Under this scenario, the optimal solutions are indicated by StackelbergCournot (SCt). In this model the profit function of retailers and their reactions are the same as the NCt scenario in subsection 5.1. Therefore, the profit function of manufacturer is rewritten as Eq. (22):

$$
\operatorname{TP}_{\mathrm{m}}(\mathrm{A}, \mathrm{t})=\theta \mathrm{m}_{0}\left(\left(\alpha_{1}+\alpha_{2}\right)+2 \frac{\mathrm{m}_{0} \lambda(\lambda-\gamma)}{1-\emptyset}+2 \delta \mathrm{A}\right)-\frac{1}{2} \mathrm{~A}^{2}-\emptyset \frac{\mathrm{m}_{0}{ }^{2} \lambda^{2}}{(1-\emptyset)^{2}}
$$

Proposition 3. Stackelberg-Cournot (SCt) solution:

Condition 1: If $\theta>\frac{0.5 \lambda}{\lambda-\gamma}$, there exist unique equilibrium as Eqs. (23-25).

$$
\mathrm{A}^{\mathrm{SCt}}=2 \theta \delta \mathrm{m}_{0}
$$

and 
$\emptyset^{\mathrm{SCt}}=\frac{2 \theta(\lambda-\gamma)-\lambda}{2 \theta(\lambda-\gamma)+\lambda}$

$\mathrm{a}_{\mathrm{i}}^{\mathrm{SCt}}=\frac{\mathrm{m}_{0}(2 \theta(\lambda-\gamma)+\lambda)}{2}$

Condition 2: If $\theta<\frac{\gamma \lambda}{2 \delta^{2}}-\frac{\alpha_{\mathrm{i}}}{2 \delta^{2} \mathrm{~m}_{0}}-\frac{\lambda^{2}}{4 \delta^{2}}$, there is no equilibrium.

Condition 3: If $\frac{\gamma \lambda}{2 \delta^{2}}-\frac{\alpha_{\mathrm{i}}}{2 \delta^{2} \mathrm{~m}_{0}}-\frac{\lambda^{2}}{4 \delta^{2}}<\theta<\frac{0.5 \lambda}{\lambda-\gamma}$, the equilibrium is as NCt which is defined by $\overline{\mathrm{SCt}}$.

Proof. To prove concavity of the profit of manufacturer w.r.t. $A$ and $\emptyset$, the Hessian for the manufacture's profit function w.r.t. $A$ and $\varnothing$ can be calculated as follows. If the Hessian is negative definite, then the manufacture's profit function is concave w.r.t. A and $\emptyset$.

$\mathrm{H}\left(\mathrm{TP}_{\mathrm{m}}\right)=\left[\begin{array}{ll}\frac{\partial^{2} \mathrm{TP}_{\mathrm{m}}}{\partial \mathrm{A}^{2}} & \frac{\partial^{2} \mathrm{TP}}{\partial \mathrm{A} \partial \emptyset} \\ \frac{\partial^{2} \mathrm{TP}}{\partial \emptyset \partial \mathrm{A}} & \frac{\partial^{2} \mathrm{TP}}{\partial \emptyset^{2}}\end{array}\right]$

Considering $\theta>\frac{0.5 \lambda}{\lambda-\gamma}$, the first-order derivative of the profit function of manufacturer w.r.t. national advertising and participation rate is as Eqs. (26-27).

$$
\begin{aligned}
& \frac{\partial \mathrm{TP}_{\mathrm{m}}(\mathrm{A}, \emptyset)}{\partial \mathrm{A}}=2 \theta \mathrm{m}_{0} \delta-\mathrm{A}=0 \\
& \frac{\partial \mathrm{TP}_{\mathrm{m}}(\mathrm{A}, \emptyset)}{\partial \emptyset}=\frac{2 \theta \mathrm{m}_{0}{ }^{2} \lambda(\lambda-\gamma)-\mathrm{m}_{0}{ }^{2} \lambda^{2}}{(1-\emptyset)^{2}}-\frac{2 \emptyset \mathrm{m}_{0}{ }^{2} \lambda^{2}}{(1-\emptyset)^{3}}=0
\end{aligned}
$$

According to Hessian matrix for the profit function of manufacture:

$$
\mathrm{H}_{11}=\frac{\partial^{2} \mathrm{TP}_{\mathrm{m}}}{\partial \mathrm{A}^{2}}=-1<0
$$

And

$$
\begin{aligned}
& \frac{\partial^{2} \mathrm{TP}_{\mathrm{m}}}{\partial \mathrm{A} \partial \emptyset}=\frac{\partial^{2} \mathrm{TP}_{\mathrm{m}}}{\partial \emptyset \partial \mathrm{A}}=0 \\
& \frac{\partial^{2} \mathrm{TP}_{\mathrm{m}}}{\partial \emptyset^{2}}=\frac{4 \mathrm{~m}_{0}{ }^{2} \lambda^{2}}{(\varnothing-1)^{3}}-\frac{6 \mathrm{~m}_{0}{ }^{2} \lambda^{2} \emptyset}{(\varnothing-1)^{4}}-\frac{4 \mathrm{~m}_{0}{ }^{2} \lambda \theta(\lambda-\gamma)}{(\varnothing-1)^{3}}
\end{aligned}
$$

Hence, $\mathrm{H}_{22}$ is positive under the following condition:

$$
\frac{6 \mathrm{~m}_{0}{ }^{2} \lambda^{2} \emptyset}{(\varnothing-1)^{4}}+\frac{4 \mathrm{~m}_{0}{ }^{2} \lambda \theta(\lambda-\gamma)}{(\varnothing-1)^{3}}>\frac{4 \mathrm{~m}_{0}{ }^{2} \lambda^{2}}{(\varnothing-1)^{3}}
$$

Obviously, the first principal minor $\left(\mathrm{H}_{11}\right)$ of the above Hessian has a negative value. The second principal minor is positive under the condition (31). Fig. 2 demonstrates the concavity of the manufacturer's profit w.r.t A, $\emptyset$. Thus, as observed, the Hessian matrix is negative definite. Therefore, the manufacturer's profit function is concave w.r.t $A, \varnothing$. 


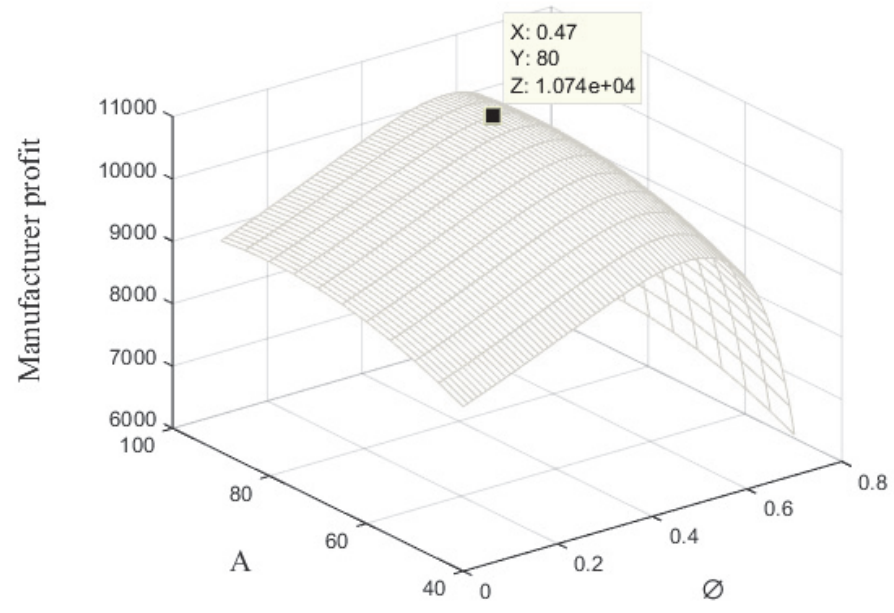

Fig. 2. Concavity of the manufacturer's profit under Stackelberg-Cournot model

Moreover, under $\theta<\frac{0.5 \lambda}{\lambda-\gamma}$ condition, $\emptyset^{\mathrm{SCt}}$ will be negative which implies that the retailer $i$ should pay $\left(\varnothing \frac{1}{2} a_{i}^{2}\right)$ to the manufacturer besides incurring local promotion effort investment $\left(\frac{1}{2} a_{i}^{2}\right)$. This is an inconsistency because our model assumes that the manufacturer shares a positive portion of local promotion effort expenditure to the retailers. Thus, the participation ratio is set to be zero. The optimal solution under this condition is the same as NCt in subsection 5.1, which is not viable under $\theta<\frac{\gamma \lambda}{2 \delta^{2}}-$ $\frac{\alpha_{i}}{2 \delta^{2} \mathrm{~m}_{0}}-\frac{\lambda^{2}}{4 \delta^{2}}$.

According to Proposition 3, under determined condition the unique equilibrium solution is reached for the investigated model where the manufacturer may offer zero or positive local promotion effort share to the retailers relative to the values of $\theta, \lambda$, and $\gamma$.

\subsection{Stackelberg-Collusion model}

Under this model, between two SC echelons the Stackelberg game is played where the manufacturer is the SC leader and the two retailers are the SC followers. Furthermore, two retailers collude with each other to obtain maximum profit and then follow the Collusion behavior. In this game, the optimal solutions are denoted by Stackelberg-Collusion ( $\mathrm{SCn}$ ). Under this scenario the profit function of retailers and their reactions are the same as the NCn scenario in subsection 5.2. Hence, the profit function of manufacturer is rewritten as Eq. (32):

$$
\operatorname{TP}_{\mathrm{m}}(\mathrm{A}, \emptyset)=\theta \mathrm{m}_{0}\left(\left(\alpha_{1}+\alpha_{2}\right)+2 \frac{\mathrm{m}_{0}(\lambda-\gamma)^{2}}{1-\emptyset}+2 \delta \mathrm{A}\right)-\frac{1}{2} \mathrm{~A}^{2}-\emptyset \frac{\mathrm{m}_{0}{ }^{2}(\lambda-\gamma)^{2}}{(1-\mathrm{t})^{2}}
$$

Proposition 4. Stackelberg-Collusion ( $\mathrm{SCn}$ ) solution:

Condition 1: If $\theta>0.5$, there exist unique equilibrium as Eqs. (33-35).

$$
\begin{aligned}
\mathrm{A}^{\mathrm{SCn}} & =2 \theta \delta \mathrm{m}_{0}, \\
\emptyset^{\mathrm{SCn}} & =\frac{2 \theta-1}{2 \theta+1}, \\
\mathrm{a}_{\mathrm{i}}^{\mathrm{SCn}} & =\frac{\mathrm{m}_{0}(2 \theta+1)(\lambda-\gamma)}{2} .
\end{aligned}
$$

Condition 2: If $\theta<0.5$, the equilibrium is as NCn which is expressed by $\overline{\mathrm{SCn}}$. 
Proof. To prove concavity of the profit of manufacturer w.r.t. $A$ and $\varnothing$, the Hessian matrix for the manufacture's profit function w.r.t. $A$ and $\varnothing$ can be calculated as follows. If the Hessian is negative definite, then the manufacture's profit function is concave w.r.t. $A$ and $\emptyset$.

$\mathrm{H}\left(\mathrm{TP}_{\mathrm{m}}\right)=\left[\begin{array}{ll}\frac{\partial^{2} \mathrm{TP}_{\mathrm{m}}}{\partial \mathrm{A}^{2}} & \frac{\partial^{2} \mathrm{TP}}{\partial \mathrm{A} \partial \emptyset} \\ \frac{\partial^{2} \mathrm{TP}}{\partial \emptyset \partial \mathrm{A}} & \frac{\partial^{2} \mathrm{TP}}{\partial \emptyset^{2}}\end{array}\right]$

when $\theta>0.5$, the first derivative of the profit function of manufacturer w.r.t. national advertising and participation rate is as follows,

$$
\begin{aligned}
& \frac{\partial \mathrm{TP}_{\mathrm{m}}(\mathrm{A}, \emptyset)}{\partial \mathrm{A}}=2 \theta \mathrm{m}_{0} \delta-\mathrm{A}=0, \\
& \frac{\partial \mathrm{TP}_{\mathrm{m}}(\mathrm{A}, \emptyset)}{\partial \varnothing}=\frac{2 \mathrm{~m}_{0}^{2} \emptyset(\lambda-\gamma)^{2}}{(1-\emptyset)^{3}}-\frac{\mathrm{m}_{0}^{2}(\lambda-\gamma)^{2}}{(1-\emptyset)^{2}}+\frac{2 \mathrm{~m}_{0}^{2} \theta(\lambda-\gamma)^{2}}{(1-\emptyset)^{2}}=0 .
\end{aligned}
$$

According to Hessian matrix for the profit function of manufacture:

$$
\begin{aligned}
& \mathrm{H}_{11}=\frac{\partial^{2} \mathrm{TP}_{\mathrm{m}}}{\partial \mathrm{A}^{2}}=-1<0, \\
& \frac{\partial^{2} \mathrm{TP}}{\partial \mathrm{A} \partial \emptyset}=\frac{\partial^{2} \mathrm{TP}_{\mathrm{m}}}{\partial \emptyset \partial \mathrm{A}}=0, \\
& \frac{\partial^{2} \mathrm{TP}_{\mathrm{m}}}{\partial \emptyset^{2}}=\frac{4 \mathrm{~m}_{0}^{2}(\lambda-\gamma)^{2}}{(1-\emptyset)^{3}}-\frac{6 \emptyset \mathrm{m}_{0}^{2}(\lambda-\gamma)^{2}}{(1-\emptyset)^{4}}-\frac{4 \mathrm{~m}_{0}^{2} \theta(\lambda-\gamma)^{2}}{(1-\emptyset)^{3}},
\end{aligned}
$$

Hence, $\mathrm{H}_{22}$ is positive under the following condition:

$$
\frac{6 \emptyset \mathrm{m}_{0}^{2}(\lambda-\gamma)^{2}}{(1-\emptyset)^{4}}+\frac{4 \mathrm{~m}_{0}^{2} \theta(\lambda-\gamma)^{2}}{(1-\emptyset)^{3}}>\frac{4 \mathrm{~m}_{0}^{2}(\lambda-\gamma)^{2}}{(1-\emptyset)^{3}}
$$

Clearly, the first principal minor $\left(\mathrm{H}_{11}\right)$ of the above Hessian has a negative value. The second principal minor is positive under the condition (41). Fig. 3 demonstrates the concavity of the manufacturer's profit w.r.t A, $\varnothing$. Thus, as observed, the Hessian matrix is negative definite. Therefore, the manufacturer's profit function is concave w.r.t A, $\emptyset$.

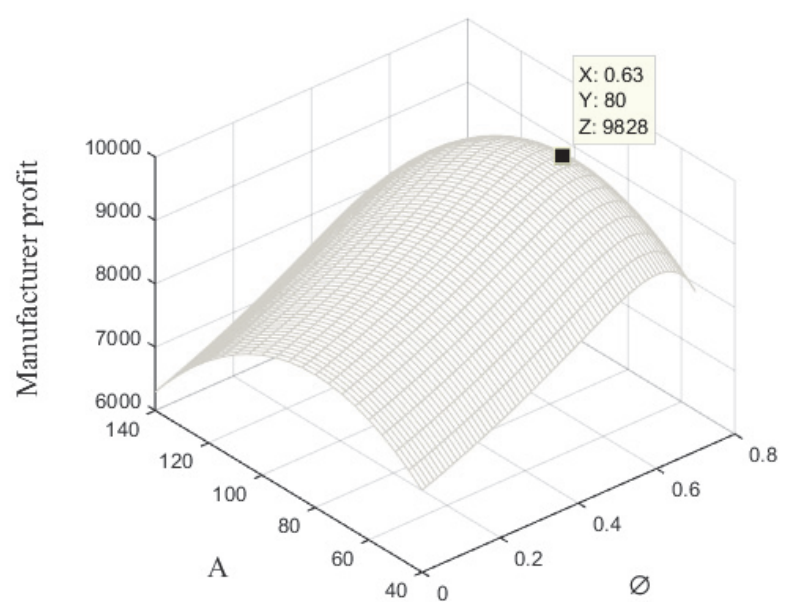

Fig. 3. Concavity of the manufacturer's profit under Stackelberg-Collusion model 
Moreover, under $\theta<0.5$ condition, $\emptyset^{\mathrm{SCn}}$ will be negative. Thus, the participation rate is set to be zero. The optimal solution under this condition is the same as NCn in subsection 5.2.

According to Proposition 4, under determined condition there is a unique equilibrium solution for the investigated model where the manufacturer may offer zero or positive local advertising shares to the retailers corresponding to the values of $\theta$. In addition, it can be concluded that under reactions of the retailers in SCt and SCn scenarios, as fraction of participation rate grows the local promotion effort expenditure by the retailers increases (i.e., $\frac{\partial \mathrm{a}_{\mathrm{i}}}{\partial \emptyset}>0$ ).

\section{Cooperation decision-making}

Under cooperation scenario, all SC members (the manufacturer and the two retailers) aim to maximize their profit from the whole SC perspective. The SC profit function is formulated as Eq. (42).

$$
\begin{aligned}
\operatorname{TP}_{S C}\left(A, a_{1}, a_{2}\right)= & \operatorname{TP}_{1}\left(a_{1}\right)+\operatorname{TP}_{2}\left(a_{2}\right)+\operatorname{TP}_{m}(A) \\
& =m_{0}(\theta+1)\left(\left(\alpha_{1}+\alpha_{2}\right)+a_{1}(\lambda-\gamma)+a_{2}(\lambda-\gamma)+2 \delta A\right)-\frac{1}{2} A^{2}-\left(\frac{1}{2} a_{1}^{2}\right)-\left(\frac{1}{2} a_{2}^{2}\right)
\end{aligned}
$$

Proposition 5. Cooperation (Co) solution:

$$
\begin{aligned}
& A^{\text {Co }}=2 m_{0}(\theta+1) \delta, \\
& a_{i}{ }^{\text {Co }}=m_{0}(\theta+1)(\lambda-\gamma) .
\end{aligned}
$$

Proof. To prove the concavity of the profit of entire $\mathrm{SC}$ w.r.t. $A$ and $\mathrm{a}_{\mathrm{i}}$, the Hessian matrix for the profit of whole SC function w.r.t. $A$ and $\mathrm{a}_{\mathrm{i}}$ can be calculated as follows. If the Hessian is negative definite, then the profit function of $\mathrm{SC}$ is concave w.r.t. A and $\mathrm{a}_{\mathrm{i}}$.

$$
\begin{gathered}
H\left(T P_{\mathrm{SC}}\right)=\left[\begin{array}{ccc}
\frac{\partial^{2} \mathrm{TP}_{\mathrm{SC}}}{\partial \mathrm{A}^{2}} & \frac{\partial^{2} \mathrm{TP}_{\mathrm{SC}}}{\partial \mathrm{A} \partial \mathrm{a}_{1}} & \frac{\partial^{2} \mathrm{TP}_{\mathrm{SC}}}{\partial \mathrm{A} \partial \mathrm{a}_{2}} \\
\frac{\partial^{2} \mathrm{TP}_{\mathrm{SC}}}{\partial \mathrm{a}_{1} \partial \mathrm{A}} & \frac{\partial^{2} \mathrm{TP}_{\mathrm{SC}}}{\partial \mathrm{a}_{1}^{2}} \frac{\partial^{2} \mathrm{TP}_{\mathrm{SC}}}{\partial \mathrm{a}_{1} \partial \mathrm{a}_{2}} \\
\frac{\partial^{2} \mathrm{TP}_{\mathrm{SC}}}{\partial \mathrm{a}_{2} \partial \mathrm{A}} & \frac{\partial^{2} \mathrm{TP}_{\mathrm{SC}}}{\partial \mathrm{a}_{2} \partial \mathrm{a}_{1}} \frac{\partial^{2} \mathrm{TP}_{\mathrm{SC}}}{\partial \mathrm{a}_{2}^{2}}
\end{array}\right] \\
\frac{\partial \mathrm{TP}_{\mathrm{SC}}\left(\mathrm{A}, \mathrm{a}_{1}, \mathrm{a}_{2}\right)}{\partial \mathrm{A}}=2 \delta(\theta+1) \mathrm{m}_{0}-\mathrm{A}=0 \\
\frac{\partial \mathrm{TP}_{\mathrm{SC}}\left(\mathrm{A}, \mathrm{a}_{1}, \mathrm{a}_{2}\right)}{\partial \mathrm{a}_{\mathrm{i}}}=\mathrm{m}_{0}(\theta+1)(\lambda-\gamma)-\mathrm{a}_{\mathrm{i}}=0
\end{gathered}
$$

According to Hessian matrix for the whole SC profit function:

$$
\begin{aligned}
& \mathrm{H}_{11}=\frac{\partial^{2} \mathrm{TP}_{\mathrm{SC}}}{\partial \mathrm{A}^{2}}=-1<0 \\
& \frac{\partial^{2} \mathrm{TP}_{\mathrm{SC}}}{\partial \mathrm{A} \partial \mathrm{a}_{\mathrm{i}}}=\frac{\partial^{2} \mathrm{TP}_{\mathrm{SC}}}{\partial \mathrm{a}_{\mathrm{i}} \partial \mathrm{A}}=0 \\
& \mathrm{H}_{22}=1>0
\end{aligned}
$$




$$
\mathrm{H}_{33}=-1<0
$$

As observed, the Hessian matrix is negative definite. Thus, the SC profit function is concave w.r.t. $A$ and $\mathrm{a}_{\mathrm{i}}$. The optimal solutions and SC participants' profit besides the whole SC profit under five game scenarios are summarized in Table 3 and Table 4, respectively.

\section{Discussion of the results}

In this section, the comparisons on the optimal solution of four game scenarios are provided. The comparisons are carried out under two parameters, $\theta$ and $\mathrm{K}$. The parameter $\mathrm{K}$, indicates the competition effect between retailers on local advertising promotion effort as defined in Eq. (51):

$$
\mathrm{K}=\lambda-\gamma \text {. }
$$

Fig. 4 illustrates the feasible regions under each scenario by considering $\theta$ and $\mathrm{K}$. The space of mentioned parameters is divided into five regions. Table 5 shows the feasibility of each game scenario under five regions. Under Nash game scenarios, $\mathrm{NCt}$ and $\mathrm{NCn}$, the participation rate of manufacturer to support ratio of local advertising of retailers is zero. While, under SCt and SCn scenarios, the manufacturer may share a positive fraction of retailers' promotion effort based on the values of $\theta$ and K. Meanwhile, only under Stackelberg game the manufacturer offer a positive promotion effort portion to retailers.

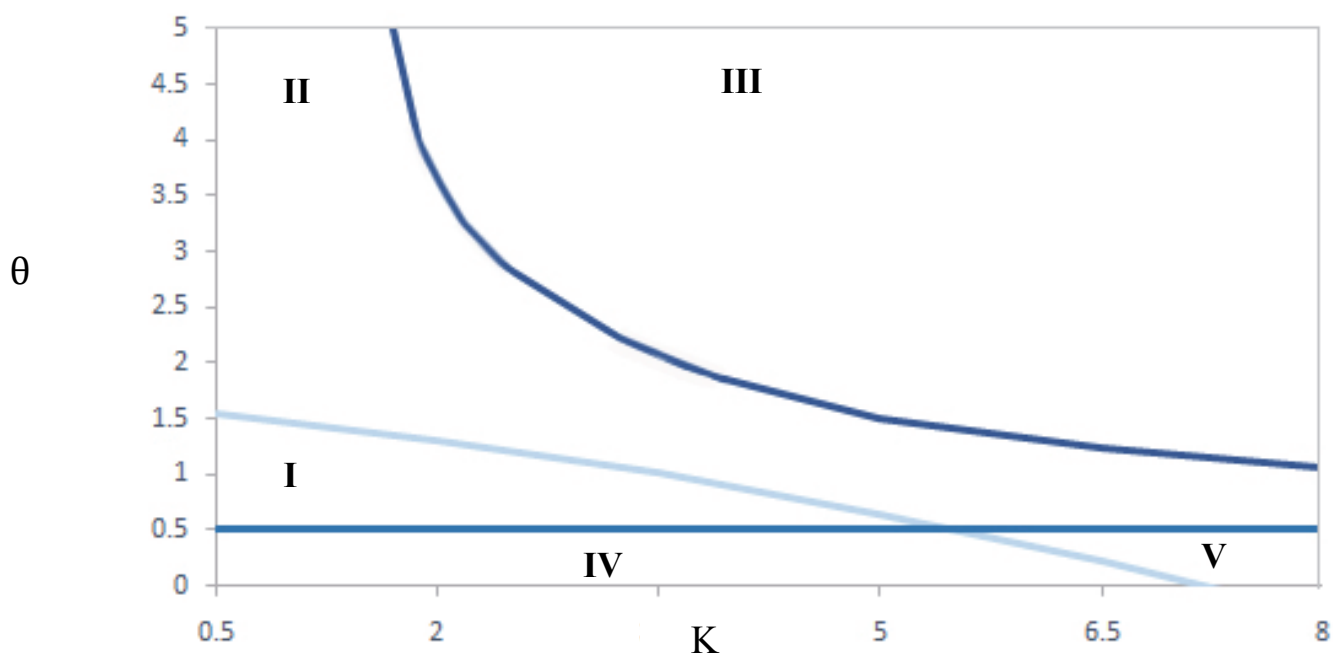

Fig. 4. The viable regions under four non-cooperative game scenarios

\section{Table 5}

The feasibility of the game scenarios

\begin{tabular}{cc}
\hline Region & Feasible Scenario \\
\hline (I) & $\mathrm{SCn}$ \\
(II) & $\mathrm{SCn}, \mathrm{NCt}, \overline{\mathrm{SCt}}$ \\
(III) & $\mathrm{SCn}, \overline{\mathrm{SCt}} \mathrm{NCt}$ \\
(IV) & $\overline{\mathrm{SCn}}$ \\
(V) & $\mathrm{NCt}, \overline{\mathrm{SCn}}$ \\
\hline
\end{tabular}




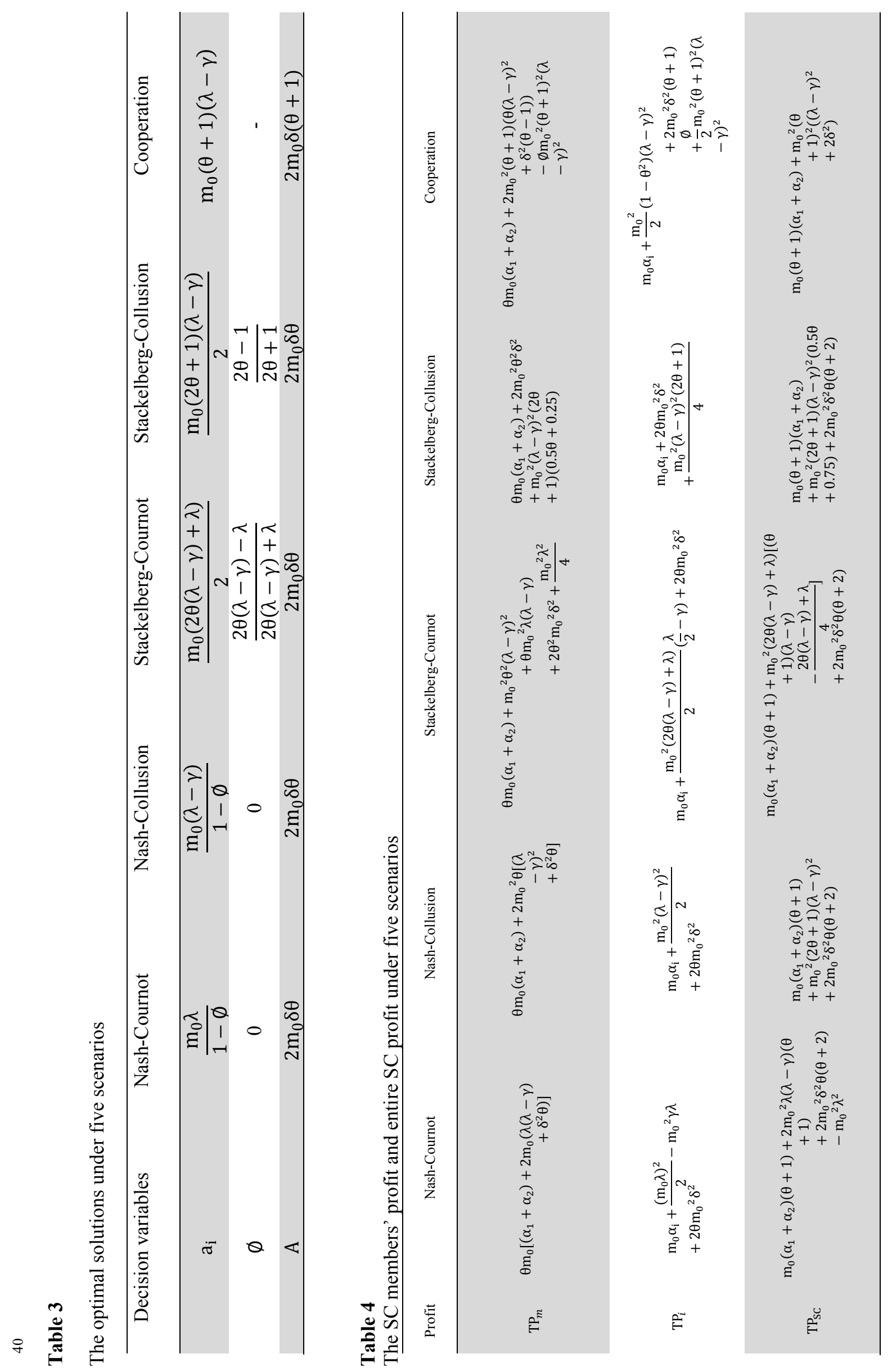




\subsection{Comparison on participation rate}

According to Table 3, the participation rate of the manufacturer on the promotion effort of the retailers equals zero in both Nash settings ( $\mathrm{NCt}$ and NCn). Under Stackelberg-Cournot and StackelbergCollusion, the behavior of the participation rate regarding $\theta$ and $\mathrm{K}$ is depicted in Fig. 5 and Fig. 6, respectively. As the degree of substitutability between two retailers diminishes, the lower participation rate is offered by the manufacturer.

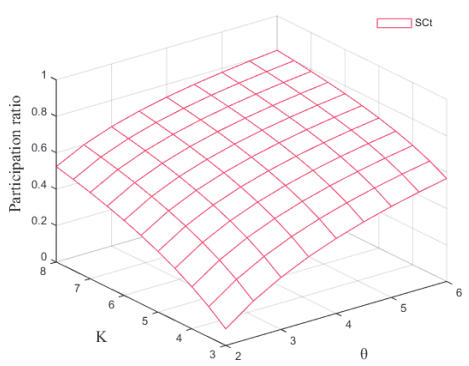

Fig. 5. Participation rate under SCt game

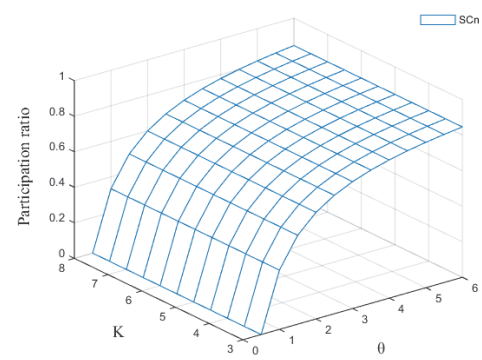

Fig. 6. Participation rate under SCn game

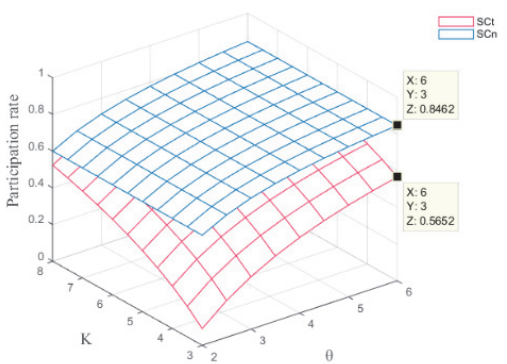

Fig. 7. Compairing participation ratio under $\mathrm{SCt}$ and $\mathrm{SCn}$ games

In addition, Fig. 7 depicts that under Stackelberg-Collusion scenario the manufacturer shares greater retailers' local advertising expenses compared to the Stackelberg-Cournot scenario. That is, $\emptyset^{\mathrm{SCn}}>$ $\emptyset^{\mathrm{SCt}}$.

\subsection{Comparison on promotion effort}

The national advertising expenditure of manufacturer under five scenarios is reached as Eq. (52).

As demonstrated in Table 3, four non-cooperative scenarios create the same national advertising investment. Under cooperative game, the highest national advertising investment is obtained.

$$
\mathrm{A}^{\mathrm{NCt}}=\mathrm{A}^{\mathrm{NCn}}=\mathrm{A}^{\mathrm{SCt}}=\mathrm{A}^{\mathrm{SCn}}=\frac{\theta}{(\theta+1)} \mathrm{A}^{\mathrm{Co}}
$$

Moreover, Fig. 8 compares the local promotion effort of retailers under five scenarios by considering $\theta$ and K. As illustrated in Fig. 8, Nash-Collusion scenario leads to the lowest local promotion effort. Whereas Cooperation and Stackelberg-Cournot scenarios create the highest local advertising expenditure for the retailers.

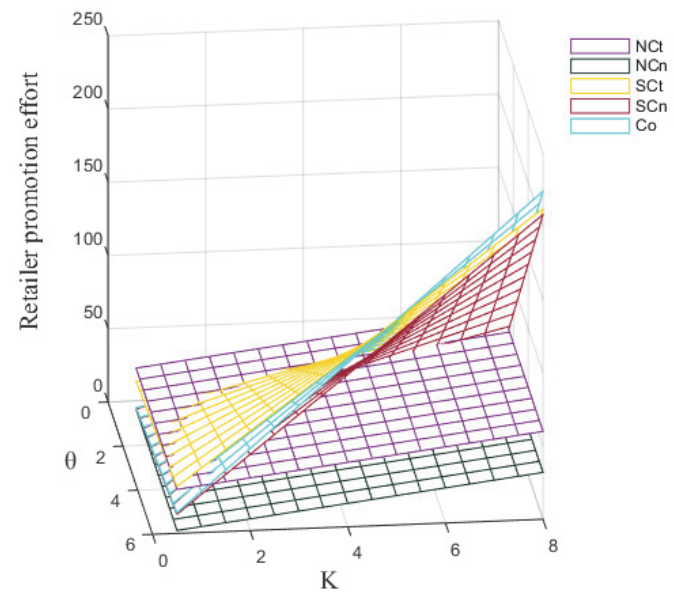

Fig. 8. Local promotion effort under five scenarios 


\subsection{Comparison on profit}

In this subsection, the optimal profit of retailers and manufacturer is analyzed under each region illustrated in Fig. 4. Fig. 9 compares the retailers' profit under feasible scenario in region (V). As indicated in Fig. 9, the retailers can achieve more profit under Nash-Collusion scenario towards NashCournot scenario. Similarly, the comparison on the manufacturer's profit in region (V) is shown in Fig. 10. The Nash-Cournot scenario is more beneficial for the manufacturer in comparison Nash-Collusion scenario.

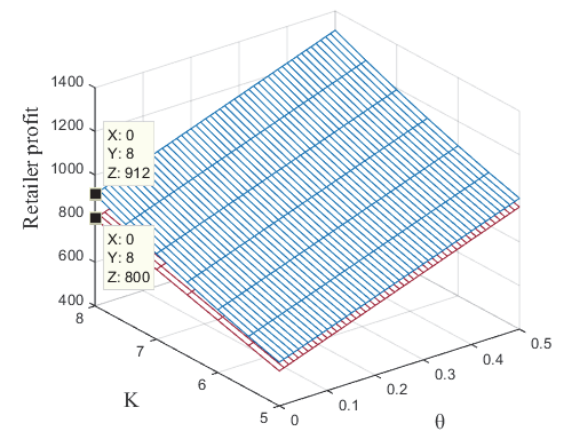

Fig. 9. Comparing retailers' profit based on region $(\mathrm{V})$

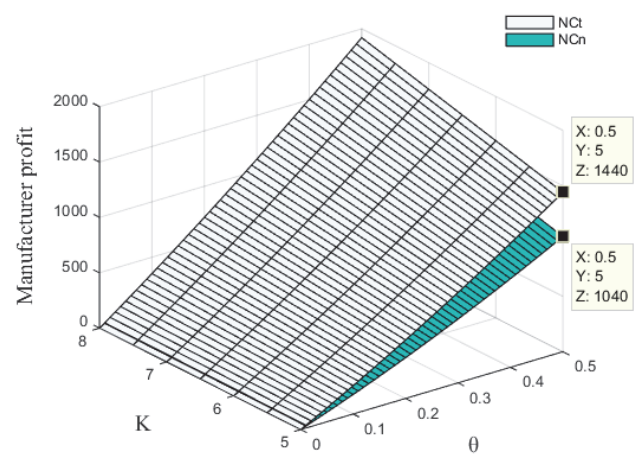

Fig. 10. Comparing manufacturer's profit based on region $(\mathrm{V})$

Moreover, in region (III), the retailers' profit along with manufacturer's profit under StackelbergCournot, Stackelberg-Collusion, and Nash-Cournot scenarios are compared in Fig. 11 and Fig. 12, respectively. The beneficial scenario for the retailers is reached Stackelberg-Collusion scenario, whereas the manufacturer tends to Stackelberg-Cournot scenario.

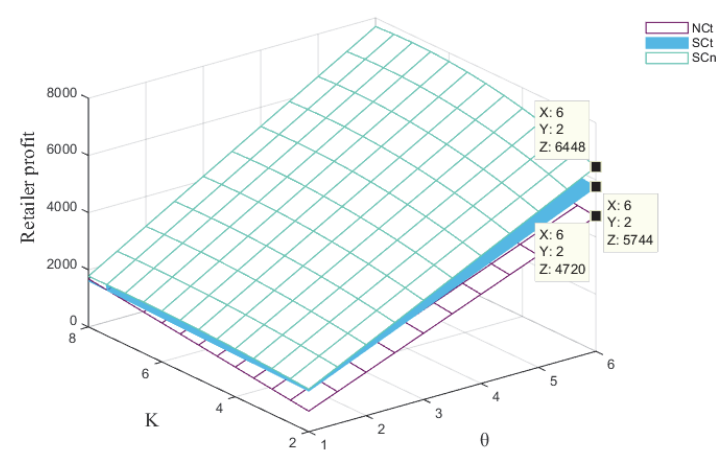

Fig. 11. Comparing retailers' profit based on region (III)

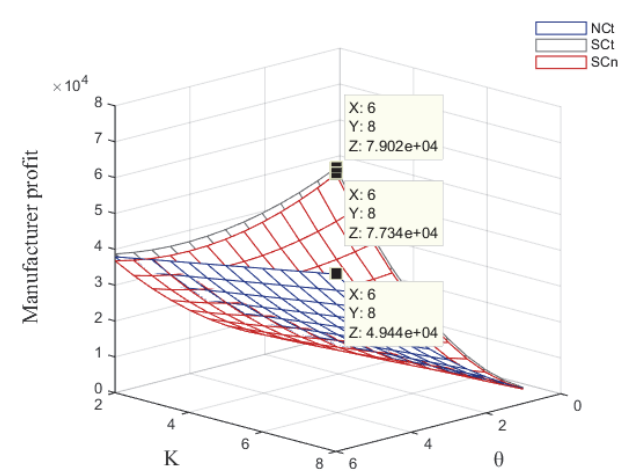

Fig. 12. Comparing manufacturer's profit based on region (III)

Furthemore, the retailers' profit besides the manufacturer's profit are analyzed under region (II) through Fig. (13) and Fig. (14), respectively. In the mentioned region both manufacturer and retailers reach the highest benefit under Stackelberg-Collusion scenario. 


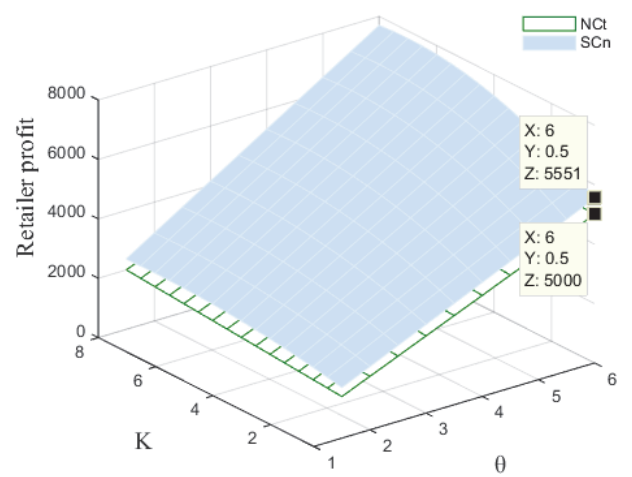

Fig. 13. Comparing retailers' profit based on region (II)

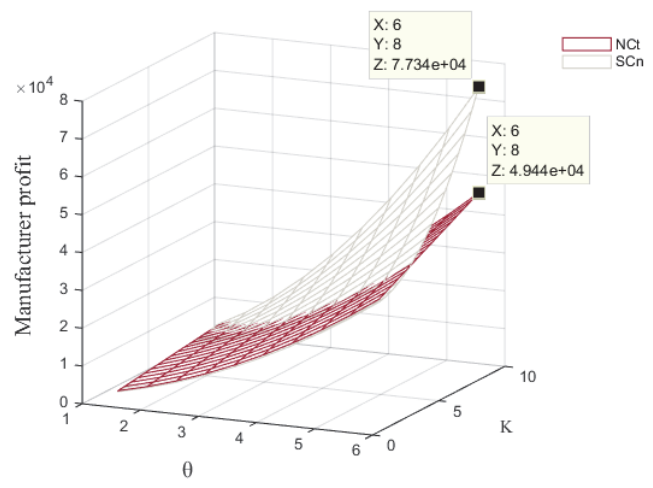

Fig. 14. Comparing manufacturer's profit based on region (II)

As a result, Table 6 summarizes the maximum profit of the SC members according to feasible regions of each scenario.

\section{Table 6}

The maximum profit of SC participants based on the five regions of Fig. 4

\begin{tabular}{ccc}
\hline Region & $\mathrm{TP}_{\mathrm{m}}^{\max }$ & \\
\hline (I) and (II) & $\mathrm{SCn}$ & $\mathrm{TP}_{\mathrm{i}}^{\mathrm{max}}$ \\
(III) & $\mathrm{SCt}$ & $\mathrm{SCn}$ \\
(IV) & $\mathrm{NCn}$ & $\mathrm{SCn}$ \\
(V) & $\mathrm{NCt}$ & $\mathrm{NCn}$ \\
\hline
\end{tabular}

\subsection{Feasibility of the cooperative scenario}

Two retailers and manufacturer will accept the joint decision-making structure when their individual profit under cooperative game is more than the non-cooperative games. Hence, in order to demonstrate that $\left(\mathrm{a}_{1}{ }^{\mathrm{Co}}, \mathrm{a}_{2}{ }^{\mathrm{Co}}, \mathrm{A}^{\mathrm{Co}}\right)$ exists, the feasibility of the cooperation game is evaluated.

$$
\begin{aligned}
& \mathrm{TP}_{\mathrm{m}}^{\mathrm{Co}} \geq \max \left\{\mathrm{TP}_{\mathrm{m}}^{\mathrm{NCt}}, \mathrm{TP}_{\mathrm{m}}^{\mathrm{NCn}}, \mathrm{TP}_{\mathrm{m}}^{\mathrm{SCt}}, \mathrm{TP}_{\mathrm{m}}^{\mathrm{SCn}}\right\} \\
& \mathrm{TP}_{\mathrm{i}}^{\mathrm{Co}} \geq \max \left\{\mathrm{TP}_{\mathrm{i}}^{\mathrm{NCt}}, \mathrm{TP}_{\mathrm{i}}^{\mathrm{NCn}}, \mathrm{TP}_{\mathrm{i}}^{\mathrm{SCt}}, \mathrm{TP}_{\mathrm{i}}^{\mathrm{SCn}}\right\}
\end{aligned}
$$

The upper bound for $\emptyset^{\mathrm{Co}}$ is derived from Eq. (53), whereas Eq. (54) determines the lower bound for $\emptyset^{\mathrm{Co}}$. In addition, the maximum profit of all SC members under each region is indicated in Table 6 . To achieve channel coordination the value of $\emptyset^{\mathrm{Co}}$ should satisfy the Eqs. (55-58).

$$
\begin{aligned}
& \underline{\emptyset}^{\mathrm{SCn}} \leq \emptyset^{\mathrm{Co}} \leq \bar{\emptyset}^{\mathrm{SCn}} \\
& \underline{\emptyset}^{\mathrm{SCn}} \leq \varnothing^{\mathrm{Co}} \leq \bar{\emptyset}^{\mathrm{SCt}} \\
& \underline{\emptyset}^{\mathrm{NCn}} \leq \emptyset^{\mathrm{Co}} \leq \bar{\emptyset}^{\mathrm{NCn}} \\
& \underline{\emptyset}^{\mathrm{NCn}} \leq \emptyset^{\mathrm{Co}} \leq \bar{\emptyset}^{\mathrm{NCt}}
\end{aligned}
$$

where

$\underline{\emptyset}^{\mathrm{NCn}}=\frac{1}{(\theta+1)^{2}}-\frac{4 \delta^{2}}{(\lambda-\gamma)^{2}(\theta+1)^{2}}-\frac{1-\theta}{\theta+1}$

$\underline{\emptyset}^{\mathrm{SCn}}=\frac{2 \theta+1}{2(\theta+1)^{2}}-\frac{4 \delta^{2}}{(\lambda-\gamma)^{2}(\theta+1)^{2}}-\frac{1-\theta}{\theta+1}$ 


$$
\begin{aligned}
\bar{\emptyset}^{\mathrm{NCt}} & =\frac{2 \theta}{\theta+1}-\frac{2 \delta^{2}}{(\lambda-\gamma)^{2}(\theta+1)^{2}}-\frac{2 \theta \lambda}{(\theta+1)^{2}(\lambda-\gamma)} \\
\bar{\emptyset}^{\mathrm{NCn}} & =\frac{2 \theta}{\theta+1}-\frac{2 \delta^{2}}{(\lambda-\gamma)^{2}(\theta+1)^{2}}-\frac{2 \theta}{(\theta+1)^{2}} \\
\bar{\phi}^{\mathrm{SCt}} & =\frac{2 \theta}{\theta+1}-\frac{2 \delta^{2}}{(\lambda-\gamma)^{2}(\theta+1)^{2}}-\frac{\theta^{2}}{(\theta+1)^{2}}-\frac{\theta \lambda}{(\lambda-\gamma)(\theta+1)^{2}}-\frac{\lambda^{2}}{4(\lambda-\gamma)^{2}(\theta+1)^{2}} \\
\bar{\emptyset}^{\mathrm{SCn}} & =\frac{2 \theta}{\theta+1}-\frac{2 \delta^{2}}{(\lambda-\gamma)^{2}(\theta+1)^{2}}-\frac{(2 \theta+1)(0.5 \theta+0.25)}{(\theta+1)^{2}}
\end{aligned}
$$

The value of $\emptyset^{\mathrm{Co}}$ should meet $0 \leq \emptyset^{\mathrm{Co}} \leq 1$. In addition, the upper bound of constraints in Eqs. (5558 ), must be positive. The satisfaction constraints hold on Eq. (55). In other words, only

$\emptyset^{\mathrm{SCn}}$ and $\bar{\emptyset}^{\mathrm{SCn}}$ are feasible according their viable regions along with two abovementioned satisfaction constraints for $\emptyset^{\mathrm{Co}}$. Furthermore, under cooperative game the achieved SC profit based on the regions (I) and (II) is as Eq. (65):

$$
\Delta \mathrm{TP}_{\mathrm{SC}}=2 \Delta \mathrm{TP}_{\mathrm{i}}+\Delta \mathrm{TP}_{\mathrm{m}}
$$

$\Delta \mathrm{TP}_{\mathrm{i}}$ and $\Delta \mathrm{TP}_{\mathrm{m}}$ are retailer i's and manufacturer's obtained profit, respectively which are calculated as Eq. (66) and Eq. (67).

$$
\begin{aligned}
& \Delta \mathrm{TP}_{\mathrm{i}}=\Delta \mathrm{TP}_{\mathrm{i}}^{\mathrm{Co}}-\Delta \mathrm{TP}_{\mathrm{i}}^{\mathrm{SCn}}, \\
& \Delta \mathrm{TP}_{\mathrm{m}}=\Delta \mathrm{TP}_{\mathrm{m}}^{\mathrm{Co}}-\Delta \mathrm{TP}_{\mathrm{m}}^{\mathrm{SCn}} .
\end{aligned}
$$

As a result, the retailer i's gain is obtained as Eq. (68)

$$
\Delta \mathrm{TP}_{\mathrm{i}}=\frac{\mathrm{m}_{0}{ }^{2}}{2}\left(1-\theta^{2}\right)(\lambda-\gamma)^{2}+2 \mathrm{~m}_{0}^{2} \delta^{2}-\frac{\mathrm{m}_{0}{ }^{2}}{4}(2 \theta+1)(\lambda-\gamma)^{2}+\frac{\emptyset}{2} \mathrm{~m}_{0}^{2}(\theta+1)^{2}(\lambda-\gamma)^{2}
$$

Similarly, the gain of manufacturer can be explained as follows:

$$
\begin{gathered}
\Delta \mathrm{TP}_{\mathrm{m}}=2 \mathrm{~m}_{0}{ }^{2} \theta(\theta+1)(\lambda-\gamma)^{2}-2 \mathrm{~m}_{0}^{2} \delta^{2}-\emptyset \mathrm{m}_{0}{ }^{2}(\theta+1)^{2}(\lambda-\gamma)^{2}-\mathrm{m}_{0}{ }^{2}(2 \theta \\
+1)(\lambda-\gamma)^{2}(0.5 \theta+0.25)
\end{gathered}
$$

Thus, the supply chain's reached profit can be calculated as follows:

$$
\begin{aligned}
\Delta \mathrm{TP}_{\mathrm{SC}}=\mathrm{m}_{0}{ }^{2} & \left(1-\theta^{2}\right)(\lambda-\gamma)^{2}+2 \mathrm{~m}_{0}{ }^{2} \delta^{2}-\frac{\mathrm{m}_{0}{ }^{2}}{2}(2 \theta+1)(\lambda-\gamma)^{2} \\
& +2 \mathrm{~m}_{0}{ }^{2} \theta(\theta+1)(\lambda-\gamma)^{2}-\mathrm{m}_{0}{ }^{2}(2 \theta+1)(\lambda-\gamma)^{2}(0.5 \theta+0.25)
\end{aligned}
$$

Accordingly, the feasibility of the cooperation game demonstrates that all SC participants are willing to cooperate. In the following section, in order to split the achieved SC profit properly the Nash bargaining model is discussed.

\section{Bargaining model}

In this section, the Nash bargaining model is established to specify the participation rate in a way that all SC members obtain more profit under cooperative game in comparison with other non-cooperative scenarios. Hence, the share of each SC member from supply chain's gain is considered according to its bargaining power. In order to calculate the agreed participation rate, according to Nash (1950), the 
utility function of the retailers and manufacturer based on the bargaining power are explained as Eqs. (71-72), respectively.

$$
\begin{aligned}
& \mathrm{u}_{\mathrm{i}}\left(\Delta \mathrm{TP}_{\mathrm{i}}\right)=\left(\Delta \mathrm{TP}_{\mathrm{i}}\right)^{\mathrm{R}_{\mathrm{i}}} \\
& \mathrm{u}_{\mathrm{m}}\left(\Delta \mathrm{TP}_{\mathrm{m}}\right)=\left(\Delta \mathrm{TP}_{\mathrm{m}}\right)^{\mathrm{R}_{\mathrm{m}}}
\end{aligned}
$$

in which, $\mathrm{R}_{\mathrm{i}}$ and $\mathrm{R}_{\mathrm{m}}$ indicate the bargaining power of retailer $i$ and manufacturer, respectively.

Thus, the utility function of entire SC is calculated as Eq. (73)

$$
\mathrm{u}_{\mathrm{SC}}=\mathrm{u}_{1}\left(\Delta \mathrm{TP}_{1}\right) \times \mathrm{u}_{2}\left(\Delta \mathrm{TP}_{2}\right) \times \mathrm{u}_{\mathrm{m}}\left(\Delta \mathrm{TP}_{\mathrm{m}}\right)=\left(\Delta \mathrm{TP}_{1}\right)^{\mathrm{R}_{1}} \times\left(\Delta \mathrm{TP}_{2}\right)^{\mathrm{R}_{2}} \times\left(\Delta \mathrm{TP}_{\mathrm{m}}\right)^{\mathrm{R}_{\mathrm{m}}}
$$

Hence, the Nash bargaining issue is determined as follows:

$$
\begin{aligned}
\Delta \mathrm{TP}_{1}^{*} & =\frac{\mathrm{R}_{1}}{\mathrm{R}_{1}+\mathrm{R}_{2}+\mathrm{R}_{\mathrm{m}}} \Delta \mathrm{TP}_{\mathrm{SC}} \\
\Delta \mathrm{TP}_{2}^{*} & =\frac{\mathrm{R}_{2}}{\mathrm{R}_{1}+\mathrm{R}_{2}+\mathrm{R}_{\mathrm{m}}} \Delta \mathrm{TP}_{\mathrm{SC}} \\
\Delta \mathrm{TP}_{\mathrm{m}}^{*} & =\frac{\mathrm{R}_{\mathrm{m}}}{\mathrm{R}_{1}+\mathrm{R}_{2}+\mathrm{R}_{\mathrm{m}}} \Delta \mathrm{TP}_{\mathrm{SC}}
\end{aligned}
$$

To solve the Nash bargaining model, the Eqs. (68-70) combines with Eqs. (74-76) and then the participation rate based on the Nash bargaining solution is achieved as Eq. (77)

$$
\begin{gathered}
\varnothing=\frac{2(1-\theta)(\mathrm{B}-0.5)}{(\theta+1)}+\frac{4 \delta^{2}(\mathrm{~B}-1)}{(\theta+1)^{2}(\lambda-\gamma)^{2}}-\frac{(2 \theta+1)(\mathrm{B}-0.5)}{(\theta+1)^{2}}+\frac{4 \mathrm{~B} \theta}{(\theta+1)} \\
-\frac{2 \mathrm{~B}(2 \theta+1)(0.5 \theta+0.25)}{(\theta+1)^{2}}
\end{gathered}
$$

where,

$$
\mathrm{B}=\frac{\mathrm{R}_{1}}{\mathrm{R}_{1}+\mathrm{R}_{2}+\mathrm{R}_{\mathrm{m}}}
$$

\section{Conclusion}

In this paper, the co-op promotion effort problem was developed in a manufacturer-retailer SC. In the investigated co-op advertising SC, the monopolistic manufacturer sells one product through two duopolistic retailers facing different market demand. The impact of both local advertising and national advertising was incorporated into market demand, simultaneously. In our co-op promotion effort SC, two retailers competed with each other on local promotion effort within the market. Furthermore, the manufacturer shared a fraction of retailers' advertising expenditures to increase the local promotion effort. The co-op advertising SC was proposed under three different decision-making models: (1) decentralized structure, (2) centralized structure, and (3) coordination structure. In the decentralized structure, the competition between two echelons was investigated through either Manufacturer Stackelberg or Nash. Moreover, either Cournot or Collusion behaviors were followed by two retailers. Afterwards, the co-op advertising SC was developed under cooperation game where all SC parties seek to reach the highest profit for the whole SC. Accordingly, a promotion cost sharing contract was suggested to achieve channel coordination within co-op advertising SC. In each game scenario considering the feasible region, the optimal solution and unique equilibrium were determined. In addition, a comparison on the advertising level of all SC members along with the value of participation rate were carried out under parameters, $\theta$ and K. Furthermore, the feasibility of the cooperative game was evaluated in order to determine the agreed participation ratio among SC members through their bargaining power in addition to distribute the extra SC benefit among all SC fairly. Our proposed co-op advertising SC has 
revealed that under Nash game between two echelons, the manufacturer did not offer any participation ratio on the local promotion effort. While, the manufacturer may support the fraction of retailers' advertising expenditures under Stackelberg game. In addition, the national advertising investment were the same under four non-cooperative games and the highest expenditure was reached under cooperative

game. Furthermore, the interest game between two echelons was determined as Stackelberg game and the collusion behavior was preferred by two retailers whereas the manufacturer was willing to adopting Cournot behavior by two retailers. The local advertising expenditure under collusion behavior of retailers was diminished towards Cournot one regardless of which kind of game was played between two levels. Also, under Nash game two retailers did not prefer to invest more in promotion effort compared to the Stackelberg game regardless of which behavior was pursued by the retailers.

This investigation can be extended by incorporating the impact of retail price as a competitive factor along with advertising. Moreover, the customer demand can be considered stochastic.

\section{Acknowledgement}

The authors would like to thank the anonymous referees for constructive comments on earlier version of this paper.

\section{References}

Alaei, S., Alaei, R.\& Salimi, P. (2014). A game theoretical study of cooperative advertising in a singlemanufacturer-two-retailers supply chain. The International Journal of Advanced Manufacturing Technology, 74(1-4), 101-111.

Aust, G., \& Buscher, U. (2012). Vertical cooperative advertising and pricing decisions in a manufacturer-retailer supply chain: a game-theoretic approach. European Journal of Operational Research, 223(2), 473-82.

Bergen, M., \& John, G. (1997). Understanding cooperative advertising participation rates in conventional channels. Journal of Marketing Research, 357-369.

Berger, P. D. (1973). Statistical decision analysis of cooperative advertising ventures. Journal of the Operational Research Society, 24(2), 207-216.

Chaab, J., \& Rasti-Barzoki, M. (2016). Cooperative advertising and pricing in a manufacturer-retailer supply chain with a general demand function; A game-theoretic approach. Computers \& Industrial Engineering, 99, 112-123.

Chaharsooghi, S. K., Heydari, J., \& Kamalabadi, I. N. (2011). Simultaneous coordination of order quantity and reorder point in a two-stage supply chain. Computers \& Operations Research, 38(12), $1667-1677$.

Chintagunta, P. K., \& Jain, D. (1992). A dynamic model of channel member strategies for marketing expenditures. Marketing Science, 11(2), 168-188.

Dai, Y., \& Chao, X. (2013). Salesforce contract design and inventory planning with asymmetric riskaverse sales agents. Operations Research Letters, 41(1), 86-91.

Dant, R. P., \& Berger, P. D. (1996). Modelling cooperative advertising decisions in franchising. Journal of the operational research society, 47(9), 1120-1136.

Giri, B. C., \& Sharma, S. (2014). Manufacturer's pricing strategy in a two-level supply chain with competing retailers and advertising cost dependent demand. Economic Modelling, 38, 102-111.

He, X., Krishnamoorthy, A., Prasad, A., \& Sethi, S. P. (2011). Retail competition and cooperative advertising. Operations Research Letters, 39(1), 11-16.

Heydari, J., Govindan, K., \& Jafari, A. (2017). Reverse and closed loop supply chain coordination by considering government role. Transportation Research Part D: Transport and Environment, 52, 379-398.

Hojati, S., Seyedhosseini, S. M., Hosseini-Motlagh, S. M., \& Nematollahi, M. (2017). Coordination and profit sharing in a two-level supply chain under periodic review inventory policy with delay in 
payments contract. Journal of Industrial and Systems Engineering, 10, 109-131.

Huang, Z., Li, S. X., \& Mahajan, V. (2002). An Analysis of Manufacturer-Retailer Supply Chain Coordination in Cooperative Advertising. Decision sciences, 33(3), 469-494.

Jørgensen, S., \& Zaccour, G. (2014). A survey of game-theoretic models of cooperative advertising. European Journal of Operational Research, 237(1), 1-14.

Johari, M., Hosseini-Motlagh, S. M., \& Nematollahi, M. (2017). Simultaneous coordination of review period and order-up-to-level in a manufacturer-retailer chain. Journal of Industrial and Systems Engineering, 10, 1-17.

Karray, S., \& Zaccour, G. (2005). A differential game of advertising for national and store brands. In Dynamic games: theory and applications. Springer US, 213-229.

Li, S. X., Huang, Z., Zhu, J., \& Chau, P. Y. (2002). Cooperative advertising, game theory and manufacturer-retailer supply chains. Omega, 30(5), 347-357.

Liu, B., Ma, X., \& Zhang, R. (2014). Joint decision on pricing and advertising for competing retailers under emergency purchasing. Economic Modelling, 39, 257-264.

Mirzaee, M., Makui, A., \& Tavakoli, E. (2012). Supply chain coordination under retail competition and advertising dependent demand. International Journal of Industrial Engineering Computations, 3(3), 383-392.

Nash Jr, J. F. (1950). The bargaining problem. Econometrica: Journal of the Econometric Society, 155162.

Nematollahi, M., Hosseini-Motlagh, S. M., \& Heydari, J. (2017). Coordination of social responsibility and order quantity in a two-echelon supply chain: A collaborative decision-making perspective. International Journal of Production Economics, 184, 107-121.

Nematollahi, M., Hosseini-Motlagh, S. M., \& Heydari, J. (2017). Economic and social collaborative decision-making on visit interval and service level in a two-echelon pharmaceutical supply chain. Journal of Cleaner Production, 142, 3956-3969.

Sajadieh, M. S., \& Jokar, M. R. A. (2009). Optimizing shipment, ordering and pricing policies in a twostage supply chain with price-sensitive demand. Transportation Research Part E: Logistics and Transportation Review, 45(4), 564-571.

SeyedEsfahani, M. M., Biazaran, M., \& Gharakhani, M. (2011). A game theoretic approach to coordinate pricing and vertical co-op advertising in manufacturer-retailer supply chains. European Journal of Operational Research, 211(2), 263-273.

Tiaojun, X., Xinxin, Y., \& Jiabao, Z. (2010). Coordination of a supply chain with advertising investment and allowing the second ordering. Technology and Investment, 1, 191-200.

Tsao, Y. C. (2015). Cooperative promotion under demand uncertainty. International Journal of Production Economics, 167, 45-49.

Tsao, Y. C., \& Sheen, G. J. (2012). Effects of promotion cost sharing policy with the sales learning curve on supply chain coordination. Computers \& Operations Research, 39(8), 1872-1878.

Wang, S. D., Zhou, Y. W., Min, J., \& Zhong, Y. G. (2011). Coordination of cooperative advertising models in a one-manufacturer two-retailer supply chain system. Computers \& Industrial Engineering, 61(4), 1053-1071.

Xie, J., \& Neyret, A. (2009). Co-op advertising and pricing models in manufacturer-retailer supply chains. Computers \& Industrial Engineering, 56(4), 1375-1385.

Yue, J., Austin, J., Wang, M. C., \& Huang, Z. (2006). Coordination of cooperative advertising in a twolevel supply chain when manufacturer offers discount. European Journal of Operational Research, $168(1), 65-85$.

Zhang, J., Gou, Q., Liang, L., \& Huang, Z. (2013). Supply chain coordination through cooperative advertising with reference price effect. Omega, 41(2), 345-353.

Zhou, Y. W., Li, J., \& Zhong, Y. (2017). Cooperative advertising and ordering policies in a two-echelon supply chain with risk-averse agents. Omega. doi:10.1016/j.omega.2017.02.005. 
(C) 2018 by the authors; licensee Growing Science, Canada. This is an open access article distributed under the terms and conditions of the Creative Commons Attribution (CC-BY) license (http://creativecommons.org/licenses/by/4.0/). 